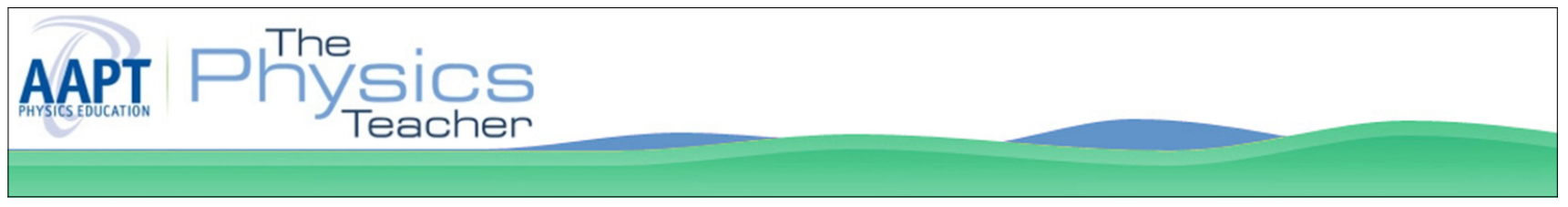

\title{
How to Use a Candle to Study Sound Waves
}

P. Simeão Carvalho, E. Briosa, M. Rodrigues, C. Pereira, and M. Ataíde

Citation: Phys. Teach. 51, 398 (2013); doi: 10.1119/1.4820847

View online: http://dx.doi.org/10.1119/1.4820847

View Table of Contents: http://tpt.aapt.org/resource/1/PHTEAH/v51/i7

Published by the American Association of Physics Teachers

\section{Related Articles}

Circuits in the Sun: Solar Panel Physics

Phys. Teach. 51, 403 (2013)

On the $\mathrm{g} / 2$ Acceleration of a Pulse in a Vertical Chain

Phys. Teach. 51, 394 (2013)

Is There a Maximum Size of Water Drops in Nature?

Phys. Teach. 51, 400 (2013)

Segmented Hoop as a Physical Pendulum

Phys. Teach. 51, 418 (2013)

Veritasium video plus analysis of falling slinky passes $1.3 \mathrm{M}$ views www.youtube.com/watch?v=uiyMuHuCFo4

Phys. Teach. 51, 382 (2013)

\section{Additional information on Phys. Teach.}

Journal Homepage: http://tpt.aapt.org/

Journal Information: http://tpt.aapt.org/about/about_the_journal

Top downloads: http://tpt.aapt.org/most_downloaded

Information for Authors: http://www.aapt.org/publications/tptauthors.cfm

\section{ADVERTISEMENT}

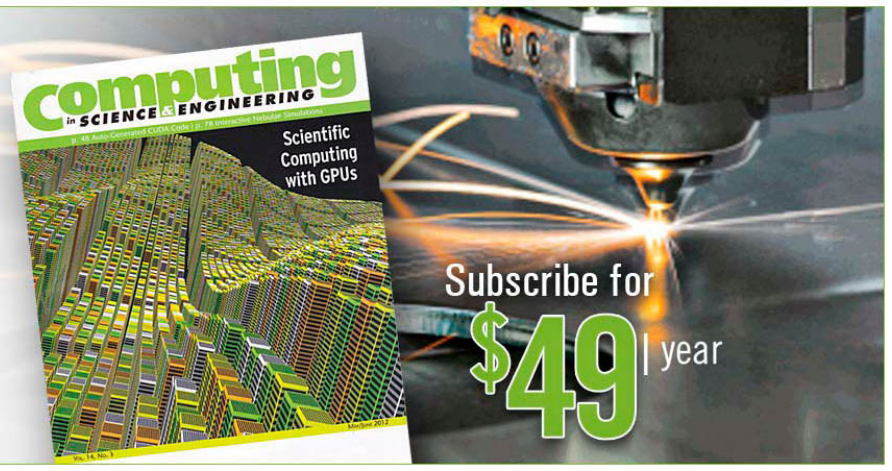




\title{
How to Use a Candle to Study Sound
} Waves

\author{
P. Simeão Carvalho, E. Briosa, and M. Rodrigues, IFIMUP, Reitoria da Universidade do Porto, Portugal \\ C. Pereïra and M. Ataíde, Escola Secundária Dr. Manuel Laranjeira, Espinho, Portugal
}

$\mathrm{I}$ $t$ is well known that sound waves in air are longitudinal waves. Although teachers use analogies such as compressing horizontal springs to demonstrate what longitudinal waves look like, students still present some difficulty in understanding that (1) sound waves correspond to oscillations of air particles, and (2) there is no "air flow" (transport of particles) in sound waves. ${ }^{1,2}$ These difficulties arise from the impossibility to actually "see" air particles moving, and from the common sense idea that free particles always have translational motion.

A simple experiment to overcome these conceptual problems can be done with a candle and a 5-V loudspeaker. ${ }^{1,3}$ The candle is put about $2.6 \mathrm{~cm}$ in front of the loudspeaker center; then a sinusoidal low-frequency signal $(\sim 10 \mathrm{~Hz}$, measured by using an analog oscilloscope), produced by a wave generator, is transformed by the loudspeaker into an infrasound wave. Although the oscillatory motion of the loudspeaker membrane is clearly visible, the absence of an audible sound lets students wonder what will happen to the flame of the candle. Our experience with students is either they believe nothing happens (no audible sound, no wave) or they expect the flame to lean away from the loudspeaker due to an invisible air pressure. The amplitude of the generated wave must be chosen to produce a visible vibration of the flame, and to avoid strong distortions of the flame's shape (this will help the video analysis of the flame's motion, as we will show in the following). The voltage to produce such a wave depends strongly on the characteristics of the loudspeaker. A very complete and interesting study concerning the flame motion behavior has been recently reported by Hrepic, Nettles, and Bonilla ${ }^{4}$ and is beyond the scope of this paper.

This experiment has a tremendous impact among students: out of nowhere, the candle's flame "magically" starts to oscillate back and forward, in a very clear longitudinal and oscillatory motion. Such observation produces an animated discussion among students due to the counterintuitive results. Immediately, they discard the idea that only audible signals perturb the air particles; secondly, the backward and forward motion of the flame dismisses the (very common) conception of a constant pressure force acting away from the speaker, and the hypothesis of a periodic oscillatory motion can now be discussed in class. In order to study the physical characteristics of the wave propagating within the air particles, students need to look in detail at how the flame oscillates.

The motion of the candle's flame was recorded at 220 frames per second with a Panasonic FZ 100 Lumix digital camera. The video was analyzed by the freeware modeling video software Tracker. ${ }^{5-7}$
Video data of the flame's oscillation can be collected with Tracker in either automatic or manual mode: automatic mode is more convenient and works better when a good contrast between the object (the flame) and the (black) background is provided; if this is not the case, then hard and painful manual work must be done. In either case, one should attend to a particular point of the flame, which must be chosen by the user (we recommend a point at one of the extremities of the flame at its mid-height, as shown in Fig. 1).

Results were analyzed using the "Data Tools" module of Tracker and show a sinusoidal-like motion of the flame (Fig. 2). A curve fit allows the determination of the wave frequency, which in this case is about $10.3 \mathrm{~Hz}$, and also the amplitude of the displacement of the flame in the horizontal direction (approximately $0.10 \mathrm{~cm}$ ). This experiment is, therefore, a very interesting and easy way for students to understand what happens with air particles when a wave propagates in that medium. It is also useful to promote peer discussion and resolve conceptual conflicts among students. In this case, we have used infrasound to cause more impact in class, but audible sound waves can also be studied with the very same experimental procedure and recommendations described above.

We can go further with this experiment and investigate how the amplitude of the displacement $(A)$ of the flame (i.e., the air molecules oscillation) changes with the distance $(d)$ to the loudspeaker (the sound source). Results of this study are presented in Fig. 3, where we can see that the experimental values of $A$ follow a reasonable linear fit with $1 / d$. The average uncertainty associated to these measurements of $A$ is

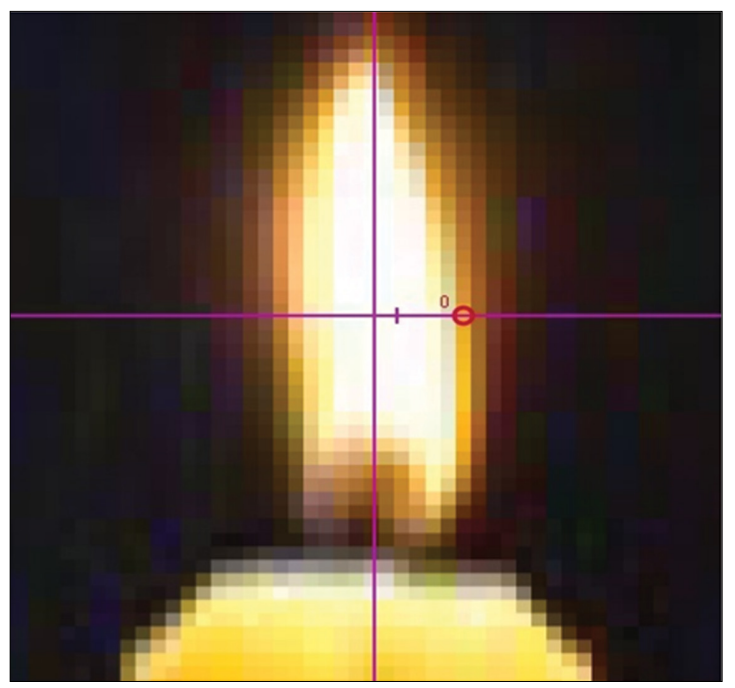

Fig. 1. Initial position at the extremity of the flame (red circle). The vertical and horizontal lines represent the reference frame. 


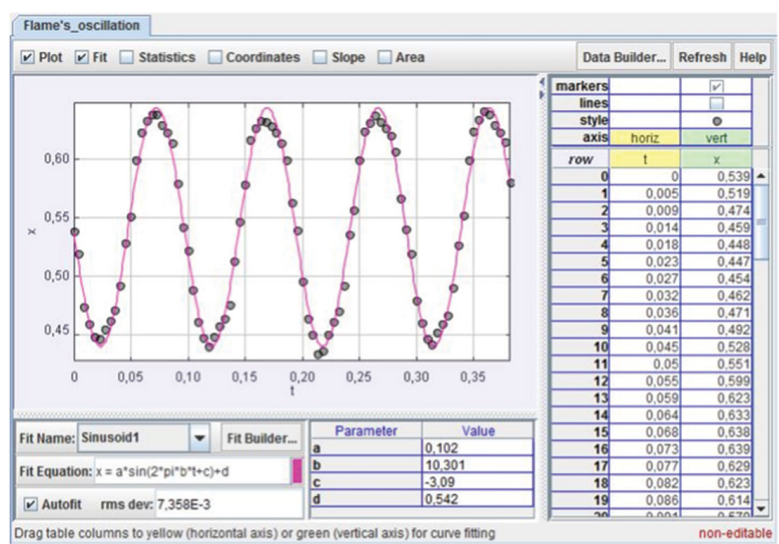

Fig. 2. Tracker's "Data Tools" analysis of the flame's oscillation, showing the amplitude in $\mathrm{cm}$ as a function of time in seconds.

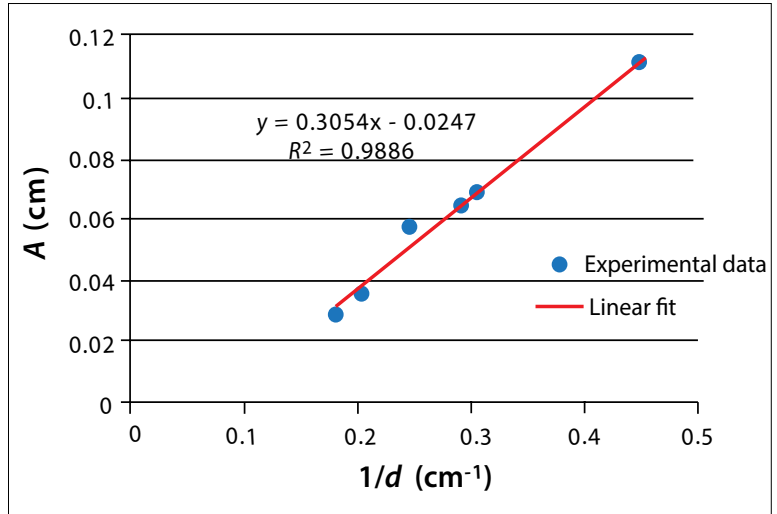

Fig. 3. Experimental data of the flame's oscillation amplitude as a function of the inverse distance to the loudspeaker. The square Pearson correlation coefficient $\left(R^{2}\right)$ suggests a good linear relationship.

equal or less than $10 \%$.

This result can be interpreted as a consequence of the propagation of sound in a three-dimensional space: the physical model for sound waves predicts that the sound intensity is proportional to $A^{2}$ and decreases with $1 / d^{2}{ }^{8}$ Therefore, the amplitude $A$ of the flame oscillation should decrease linearly with $1 / d$, which is exactly what we have obtained experimentally. The additional educational interest of this study is to provide experimental evidence of the inverse law dependence of air particles' motion amplitude, compared to the wellknown inverse square law for sound and light intensity. This experiment helps students understand that molecular motion has a different behavior with distance when compared to sound intensity.

\section{Conclusion}

With this simple experiment, students can: (1) "see" the effect of air particles in motion; (2) conclude that infrasound waves, like audible sound waves, are periodic; (3) identify that the air particles' displacement is longitudinal, and therefore sound is a longitudinal wave; and (4) study the inverse relationship concerning the amplitude of the flame's dis- placement and the distance between the flame and the loudspeaker. The experimental setup provides a good opportunity to explore sound waves in a classroom, in a very original and engaging way.

\section{References}

1. Michael Wittmann, Richard N. Steinberg, and Edward F. Redish, "Understanding and affecting student reasoning about sound waves," Int. J. Sci. Educ. 25 (8), 991 (2003).

2. Zdeslav Hrepic, Dean A. Zollman, and N. Sanjay Rebello, "Identifying students' mental models of sound propagation: The role of conceptual blending in understanding conceptual change," Phys. Rev. ST Phys. Educ. Res. 6 (2), 020114 (2010).

3. Edward F. Redish, Teaching Physics with the Physics Suite (Wiley, New York, 2003), pp. 154-156.

4. Zdeslav Hrepic, Corey Nettles, and Chelsea Bonilla, "Demonstrating sound wave propagation with candle flame and loudspeaker," Phys. Teach. 51, 16-19 (Jan. 2013).

5. D. Brown, "Video Modeling: Combining Dynamic Model Simulations with Traditional Video Analysis," presented at the 2008 AAPT Summer Meeting, Edmonton, AB, Canada.

6. D. Brown and Anne J. Cox, "Innovative uses of video analysis," Phys. Teach. 47, 145-150 (March 2009).

7. The video is available at the URL: www.fc.up.pt/pessoas/ psimeao/video/Video_oscillating_candle_220fps.mp4.

8. Hugh D. Young and Roger A. Freedman, University Physics, 9th ed. (Addison-Wesley, New York, 1996), pp. 646-653. 